\title{
Adsorption of 2-mercaptobenzthiazol on copper and MNZh-5-1 alloy and their protection from corrosion in aqueous solutions ${ }^{1}$
}

\section{Yu.I. Kuznetsov, M.O. Agafonkina, N.P. Andreeva and D.B. Vershok*}

A.N. Frumkin Institute of Physical Chemistry and Electrochemistry, Russian Academy of

Sciences, Leninsky pr. 31, 119071 Moscow, Russian Federation

*E-mail: dvershok@mail.ru

\begin{abstract}
The adsorption, passivation and protective properties of 3-amino-1,2,4-triazole (3-AT) and 2mercaptobenzothiazole (2-MBT) on copper and MNZh 5-1 alloy were studied. The adsorption characteristics of both compounds on reduced and oxidized surfaces of copper and its alloy were calculated. On oxide-free surfaces $(E=-0.60 \mathrm{~V})$ of both metals, physical adsorption of 3AT and 2-MBT occurs, whereas chemical adsorption occurs on oxidized surfaces $(E=0.0 \mathrm{~V})$. The free energies of adsorption calculated by two independent methods, ellipsometry and electrochemical impedance spectroscopy, correlate well with each other. The orientation of the studied compounds on the metal surface was revealed by the ellipsometric method. 2-MBT on reduced and oxidized surfaces of the MNZh 5-1 alloy and copper is adsorbed in planar orientation, forming bonds with the surface through sulfur and nitrogen atoms. 3-AT on cathodically reduced surface of the alloy and copper is in planar orientation, whereas at the anodic potential, in a nearly vertical orientation. 2-MBT is adsorbed on oxidized copper better than 3-AT, apparently due to interaction with its oxide. It allows a protective coating to be formed on the surface that protects the metal well even at high chloride concentrations. Corrosion tests of copper and its alloy in 3.5\% sodium chloride solution confirmed the high protective properties of 2-MBT. The created inhibitor mixture of 2-MBT with sodium laurate in equimolar ratio at a total concentration of 0.20 and $0.25 \mathrm{mmol} / \mathrm{L}$ allows one to achieve almost complete protection of copper and its alloy with $Z=99.1-99.3 \%$, respectively.
\end{abstract}

Keywords: corrosion inhibitor, degree of protection, ellipsometry, impedance, passivity, free adsorption energy, 3-amino-1,2,4-triazole, 2-mercaptobenzothiazole.

Received: March 2, 2020. Published: March 12, 2020

doi: $\underline{10.17675 / 2305-6894-2020-9-1-23}$

\footnotetext{
${ }^{1}$ The materials of the article were obtained in the framework of the Fundamental Scientific Research Program of the State Academies of Sciences for 2013-2020: "Development of the fundamental scientific foundations of the protective effect of metal corrosion inhibitors in gas and condensed media, nanocomposites, paints and conversion coatings" (State registration number AAAA-A18-118121090043-0).
} 


\section{Introduction}

Due to high electrical and thermal conductivity, copper and its alloys are widely used as structural materials in water cooling systems and in electrical and radio engineering devices, as well as in instrument-making industry [1]. In humid atmospheres, a layer of corrosion products (patina) is formed on copper and partially protects it from corrosion [2]. In an aqueous medium containing corrosive chloride ions, surface activation occurs, which increases the rate of corrosion damage. To protect copper and its alloys, corrosion inhibitors (CIs) are often used under these conditions.

Heterocyclic compounds containing elements such as N, S, and $\mathrm{O}$ are often effective CIs due to the interaction of these active centers with copper upon adsorption on the surface of a metal (alloy) and formation of a film of complex compounds with $\mathrm{Cu}(\mathrm{I})$. The most widely used CI for copper is 1,2,3-benzotriazole (BTA), which has been known in this function since 1947 [3]. Extensive research and practical application of BTA, as well as other triazoles, have been repeatedly covered in the literature and is currently continuing [4-14]. Recently, however, CIs for copper belonging to the class of triazoles have been criticized because of their high toxicity. In this regard, the authors' claim [15] is noteworthy that in many cases some substituted thiazoles can be excellent replacements for toxic triazoles.

Among the thiazoles used to protect copper, 2-mercaptobenzothiazole (2-MBT) has long been known. Even J. Bregman [16] called 2-MBT the best CI for water recycling systems. It was later confirmed that 2-MBT is one of the best CIs for copper among substituted benzothiazoles in solutions of $0.5 \mathrm{M} \mathrm{NaH}_{2} \mathrm{PO}_{4} \cdot 2 \mathrm{H}_{2} \mathrm{O}$ with pH $11.4[17,18]$ and much more effective than BTA not only in alkaline but also in acidic environments [19].

In neutral solutions, this CI is studied less thoroughly, apparently due to its low solubility in water that can however be increased by conversion to the sodium salt or by using an additional organic solvent. For example, Japanese researchers [20] showed that 2MBT forms a protective film on a $\mathrm{Cu}_{2} \mathrm{O}$ layer in its solution at $t>50^{\circ} \mathrm{C}$. It turned out that it can also be formed at room temperature if acetone $(\sim 20 \mathrm{wt} . \%)$ is added to the solution. The authors noted that 2-MBT is more effective than BTA in the chemical-mechanical polishing of copper, provided that there is no $\mathrm{H}_{2} \mathrm{O}_{2}$ in the polishing formulation. Kazansky et.al. [21], who studied the behavior of copper in a neutral water-ethanol phosphate solution containing 2-MBT, showed that its adsorption occurs with formation of a chemical compound of $\mathrm{Cu}(\mathrm{I})$ cations with exo-sulfur and nitrogen atoms of the $\mathrm{CI}$. The protective layer of a copper complex, presumably of polymeric nature $[\mathrm{Cu}(\mathrm{I}) \mathrm{MBT}]$, reaches a thickness of 8-9 $\mathrm{nm}$ after 12 hours of immersion of the electrode to the solution.

The interest in 2-MBT persists in our time. Recently, the in situ ellipsometric method, which has proven itself in the study of various organic CIs, was used for the first time to show that 2-MBT adsorption on a pre-oxidized copper electrode at $E=0.0 \mathrm{~V}$ in a neutral (pH 7.40) borate buffer is described by the logarithmic Temkin equation [22]. The free adsorption energy calculated from it, $\left(-\Delta G_{\mathrm{a}}^{0}\right)>68 \mathrm{~kJ} / \mathrm{mol}$, is significantly higher than in 
the case of BTA and leaves no doubt about the chemisorption of these CIs on the oxidized surface of copper. In [23], 2-MBT was studied as a CI for copper in $3.0 \% \mathrm{NaCl}$ solution. It was shown that after 100 hours of exposure in the inhibited solution, it reduces the roughness of the metal surface and slows down both electrode reactions, i.e. acts as a mixed type CI. The thickness of the protective layer formed by 2-MBT on copper was estimated to be $1.5 \pm 0.5 \mathrm{~nm}$.

The results of studying copper alloys in a neutral solution and in the presence of 2MBT are also noteworthy. In fact, in [24] the surface of brass $(80 \mathrm{Cu} / 20 \mathrm{Zn})$ exposed to water and various aqueous solutions was studied by XPS method. Dezincification of the surface layer was observed in pure water and in borate solutions ( $\mathrm{pH} 6.50,7.40$, and 9.10). In contrast, in a $0.5 \mathrm{M}$ solution of $\mathrm{NaCl}$ or $\mathrm{Na}_{2} \mathrm{SO}_{4}$, when brass is exposed to corrosive anions $\mathrm{Cl}^{-}$or $\mathrm{SO}_{4}^{2-}$, copper is removed from the surface layer of brass, i.e. its "decopperification" occurs. Exposure of brass in a $0.05 \mathrm{mmol} / 12$ 2-MBT solution slows down the oxide growth and results in formation of a complex $\left[\mathrm{Cu}_{x} \mathrm{Zn}_{0.5(1-x)} \mathrm{MBT}\right]$, where $x>0.5$, possibly of polymer nature, that is capable of protecting copper from corrosion.

The purpose of this article is to study the adsorption of 2-MBT from a borate buffer solution ( $\mathrm{pH}$ 7.40) on copper, an uncoated oxide film and on MNZh-5-1 alloy, which is often used in heat transfer equipment, as well as the inhibition of corrosion of these structural materials in $3.5 \% \mathrm{NaCl}$ aqueous a solution with this compound.

\section{Experimental}

Studies of the adsorption of commercial compounds, i.e., 3-amino-1,2,4-triazole (3-AT, Sigma Aldrich, CAS 61-82-5, Product of China) and 2-mercaptobenzothiazole (2-MBT, Sigma Aldrich, CAS 149-30-4, Product of China) were carried out by two independent methods in a borate buffer solution with $\mathrm{pH} 7.40$. In one of the methods, the in situ ellipsometric method, electrodes made of M-1 copper $(\mathrm{Cu}+\mathrm{Ag}-99.9 \%$, GOST 859-2014) and the MNZh 5-1 alloy (copper-nickel-iron containing more than 90\% Cu (GOST 4922006) were used.

Ellipsometric studies were carried out on an RR 2000 handheld ellipsometer in an electrochemical cell, which makes it possible to simultaneously maintain the electrode potential from the potentiostat PAR model 173 and measure the phase shift angle $\Delta$ and polarization restoration angle $\Psi$.

The accuracy in determining the angles is $\pm 0.05^{\circ}$. These angles describe the surface of the electrode and depend on its potential and on the solution composition, including the addition of a CI. With a growth of an oxide or adsorption film on the electrode surface, the angle $\Delta$ decreases, and the magnitude of the angle change $\delta \Delta$ is proportional to the thickness of the growing film, $d$. At $d \leq 10 \mathrm{~nm}$, the Drude equation holds for a uniform film:

$$
d=-\alpha \delta \Delta=-\alpha\left(\Delta-\Delta_{0}\right)
$$


where $\alpha$ is the proportionality coefficient, $\Delta_{0}$ is the angle value for the initial surface, and $\Delta$ is the angle value during the experiment. To obtain the CI adsorption isotherm, we add its concentrate in portions to the background solution. For each concentration, the $\Delta$ angle decreases in time and stops changing after a while. Thus, we determine $(-\delta \Delta)$ to build the dependence of $(-\delta \Delta)$ on the CI concentration, $C_{\mathrm{in}}$. The value of $C_{\mathrm{in}}$ at which the changes in the $\Delta$ angle cease corresponds to the formation of a monolayer. For this $(-\delta \Delta)$ value, the degree of electrode surface coverage with an adsorbate is $\theta \rightarrow 1$. The experimental dependence of $(-\delta \Delta)$ on $\log C_{\text {in }}$ is rearranged into the adsorption isotherm $\theta-f(\log C)$ and the equation describing it is determined. In the cases under consideration, the adsorption of the $\mathrm{CI}$ is adequately described by the complete Temkin equation:

$$
\theta=\frac{1}{f} \ln \frac{1+B_{\max }(C)}{1+B_{\min }(C)}
$$

where $f$ is the surface inhomogeneity factor characterizing the change in the enthalpy of adsorption with surface coverage; $B_{\max }$ and $B_{\min }$ are the adsorption equilibrium constants corresponding to the highest and lowest values of adsorption energy. The value of $B$ is associated with the free energy of adsorption by the ratio:

$$
B=\left[\exp \left(-\Delta G_{\mathrm{a}}^{0}\right) / R T\right] / 55.5
$$

The technique described previously in [11] was used to determine $-\Delta G_{\mathrm{a}, \min }^{0},-\Delta G_{\mathrm{a}, \max }^{0}$, the $f$ coefficient, $B_{\max }$, and $B_{\min }$.

Adsorption studies by the electrochemical impedance spectroscopy (EIS) method were carried out on an M1 copper electrode, which was mounted with epoxy resin into a polypropylene holder so that its working surface was the base of the cylinder $\left(S_{\mathrm{Cu}}=0.28 \mathrm{~cm}^{2}\right)$. The electrodes were polished with emery paper of different grades, up to P1000 paper, and then degreased with acetone. All experiments were performed using the Solartron Schlumberger computerized electrochemical interface (United Kingdom), which consists of a 1286 potentiostat and a FRA 1250 frequency response analyzer.

To record the spectrum, we used a glass cell with a volume $V=0.05 \mathrm{~L}$ with separated cathodic and anodic spaces. Electrochemical impedance spectra were obtained in the frequency range $\omega$ from $10 \mathrm{kHz}$ to $0.1 \mathrm{~Hz}$ with an voltage amplitude of $10 \mathrm{mV}$. The working and auxiliary electrodes (a platinum mesh with an area of $S_{\mathrm{Pt}}=20 \mathrm{~cm}^{2}$ ) were placed coaxially in the electrochemical cell. The potentials of the copper electrode were measured relative to a silver chloride reference electrode and converted to the normal hydrogen scale. The studies were carried out in borate buffer solution with $\mathrm{pH} 7.40$ under natural aeration.

At the beginning of the measurements, the working electrode was kept in borate buffer solution for $15 \mathrm{~min}$ at $E=-0.70 \mathrm{~V}$ in order to remove the air-formed oxide and obtain a clean copper surface. After that it was switched to the working potential and kept for $1 \mathrm{~h}$. Then, the spectrum was recorded in the background solution. After this, when CI 
was introduced, the electrode was kept for $1 \mathrm{~h}$ in the solution, and a spectrum was obtained at a predetermined $C_{\text {in }}$, which, after reaching a steady-state measured value, was increased by adding a new portion of CI concentrate. To determine the elements of the equivalent electrical circuits (EEC), the results were processed using the ZView program.

The degree of coverage of the electrode surface with an inhibitor was calculated by the equation

$$
\theta=\frac{C_{0}-C_{\mathrm{x}}}{C_{0}-C_{\max }}
$$

where $C_{0}, C_{\mathrm{x}}, C_{\max }$ - the capacity of the double electric layer $(d l)$, respectively, in the background solution, in the presence of $\mathrm{CI}$ in the solution and with the degree of coverage of the surface with the latter close to 1 . The value of the capacity of the $d l$, which no longer decreased with a further increase in the $C_{\text {in }}$ in the solution, was taken. The value was calculated in the same way as for the ellipsometry method according to Equations 2, 3 for the Temkin isotherm.

Polarization curves were recorded using an IPC-PRO potentiostat on an electrode made of M1 copper $\left(S=0.75 \mathrm{~cm}^{2}\right)$ or MNZh 5-1 alloy $\left(S=0.50 \mathrm{~cm}^{2}\right)$ in an electrochemical cell with divided electrode spaces. The working electrode was preliminarily polished on sandpaper with different grain sizes and degreased with acetone. The potentials $E$ of the electrode in solution were measured relative to the silver chloride reference electrode, and their values in the article are reported in the standard hydrogen scale. The auxiliary electrode was made of pyrographite.

After removing the air-formed copper oxide film (keeping the electrode for $15 \mathrm{~min}$ at $E=-0.65 \mathrm{~V}$ in borate buffer with $\mathrm{pH} 7.40$ containing $0.01 \mathrm{M} \mathrm{NaCl}$ ), the potentiostat was switched off and a free corrosion potential $E_{\text {cor }}$ was established. After the inhibitor was added to the buffer solution and a new $E_{\text {cor }}$ value established, polarization curves were recorded at a potential scan rate of $0.2 \mathrm{mV} / \mathrm{s}$. The potential of copper local depassivation by chlorides $\left(E_{\mathrm{ld}}\right)$ was determined by a sharp increase in current on the polarization curve with subsequent visual identification of pits on the electrode surface. The error in the $E_{\mathrm{ld}}$ measurement was $0.01 \mathrm{~V}$. The ability of an inhibitor to prevent local depassivation of copper was determined by the displacement of $E_{\mathrm{ld}}$ relative to $E_{\mathrm{ld}}$ in the initial borate buffer containing $0.01 \mathrm{~mol} / 1 \mathrm{NaCl}: \Delta E=E_{\mathrm{ld}}^{\text {in }}-E_{\mathrm{ld}}^{\text {background }}$

Corrosion tests were conducted on plates of M1 copper $\left(S=38 \mathrm{~cm}^{2}\right)$ and MNZh-5-1 $\left(S=25 \mathrm{~cm}^{2}\right)$ in $3.5 \% \mathrm{NaCl}$ solution without and with the CI. The corrosion rate was determined gravimetrically, by the decrease in the mass of the sample after 7 days of testing. The degree of protection $Z$ was calculated by the formula

$$
Z=\frac{K_{0}-K_{\text {in }}}{K_{0}} \cdot 100 \%
$$

where $K_{0}$ is the corrosion rate without the CI and $K_{\text {in }}$ is the corrosion rate with the CI. 


\section{Results and Discussion}

\section{Copper}

Adsorption of organic CIs, for example, various azoles [11-13, 18, 22, 25-29], from a borate buffer solution with $\mathrm{pH} 7.40$ on copper was mainly studied in situ by ellipsometric method at an electrode potential of $E=0.0 \mathrm{~V}$. The adsorption studies was often supplemented by results of studying the composition of passivating layers on copper ex situ by the XPS method [12, 22, 25, 26, 28, 29]. It was recently shown [28] that additional information on the adsorption of azoles on copper can also be obtained by another in situ method - EIS whose measurement results are consistent with ellipsometric adsorption measurements. Based on the calculation results for the EIS and reflection angles for ellipsometry, adsorption isotherms were built for 3-AT and BTA, which showed the similarity of the adsorption measurement results by the two independent methods. In all the cases studied, isotherms were adequately described by Eq. (2). It was shown that at $E=$ $-0.60 \mathrm{~V}, 3-\mathrm{AT}$ is adsorbed on the oxide-free surface of copper better than BTA, which, judging by the values of $\left(-\Delta G_{\mathrm{a}, \max }^{0}\right)=27$ and $32 \mathrm{~kJ} / \mathrm{mol}$ calculated from the results of ellipsometric measurements and EIS, respectively, does not give reason to consider its interaction with the surface as chemisorption. The adsorption of 3-AT measured by the EIS method under the same conditions is characterized by $\left(-\Delta G_{\mathrm{a}, \max }^{0}\right)=40.8 \mathrm{~kJ} / \mathrm{mol}$, which indicates a high probability of chemisorption of this CI. On a pre-oxidized electrode at $E=0.0 \mathrm{~V}$, the adsorption of both triazoles also increases, and according to ellipsometric measurements, $\left(-\Delta G_{\mathrm{a}, \max }^{0}\right)=52.5$ and $59.3 \mathrm{~kJ} / \mathrm{mol}$ for BTA and 3 -AT, respectively. Thus, despite the greater hydrophilicity of 3-AT compared to BTA, it is more strongly adsorbed on copper, so it is interesting to compare its adsorption with that of 2-MBT.

The Nyquist plots or hodographs obtained by adsorption of 2-MBT on oxidized copper at $E=0.0 \mathrm{~V}$ have the shape of two elongated semicircles (Figure 1a). The first semicircle determines the parameters of the $\mathrm{Cu}_{2} \mathrm{O}$ oxide coating formed at this potential, and the second one determines the characteristics of the double layer. These hodographs can be described using the known EEC of an oxide coated electrode [33]. In the EEC of an oxidized copper electrode at $E=0.0 \mathrm{~V}$ in a borate buffer solution with $\mathrm{pH} 7.4$ shown in Figure $1 \mathrm{~b}, R_{\mathrm{s}}, R_{\mathrm{c}}$, and $R_{\mathrm{t}}$ are the solution, coating, and charge transfer resistances, and $Q_{\mathrm{c}}$ and $Q_{\mathrm{dl}}$ are the coating capacitance and $d l$ capacitance, respectively, expressed as constant phase elements. The value of $Q_{\mathrm{dl}}$ is related to the true capacity of the double layer by the equation

$$
C_{\mathrm{dl}}=\left(Q_{\mathrm{dl}} \cdot R_{\mathrm{t}}\right)^{(l / n)} / R_{\mathrm{t}}
$$

where $n$ is a power-law coefficient that takes the surface inhomogeneity into account.

The calculation of the parameters of the adsorption isotherm (Figure 1c, curve 1) shows that the free adsorption energy on the oxidized surface of copper reaches $\left(-\Delta G_{\mathrm{a}, \max }^{0}\right)=68.4 \mathrm{~kJ} / \mathrm{mol}$. The results obtained by ellipsometry give values $\left(-\Delta G_{\mathrm{a}, \max }^{0}\right)=$ $69.0 \mathrm{~kJ} / \mathrm{mol}$ (Table 1), which shows good convergence of the methods of ellipsometry and 
EIS in this case. These values of the free energy of adsorption indicate the existence of a chemical interaction of 2-MBT with the oxidized surface of copper at $E=0.0 \mathrm{~V}$.

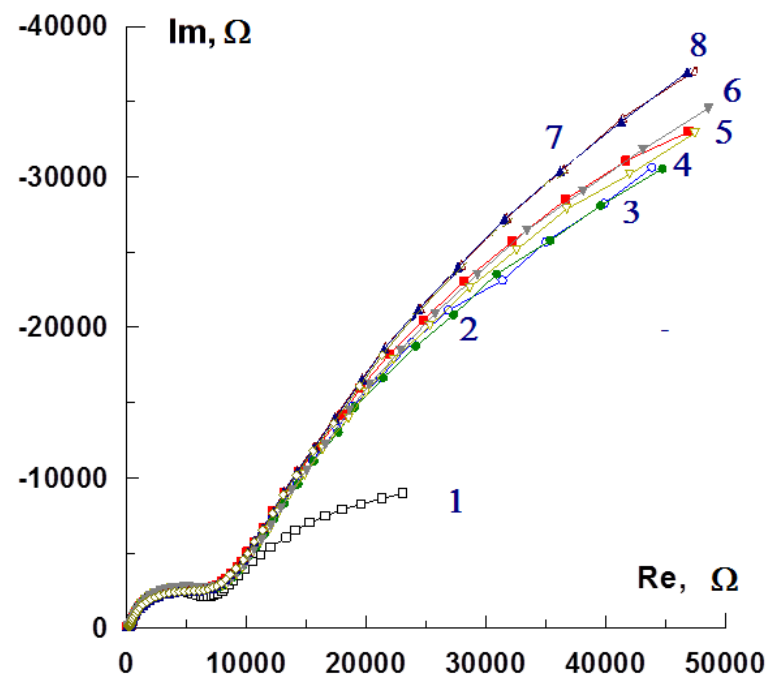

Figure 1a. Nyquist plots of oxidized copper electrode at $E=0.0 \mathrm{~V}$ in borate buffer solutions without (1) and with 2-MBT (in mol/l): $2-5.0 \cdot 10^{-12}, 3-1.0 \cdot 10^{-11}, 4-1.5 \cdot 10^{-11}, 5-$ $2.0 \cdot 10^{-11}, 6-2.5 \cdot 10^{-11}, 7-3.5 \cdot 10^{-11}, 8-4.9 \cdot 10^{-11}$.

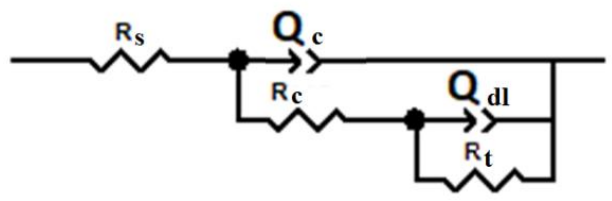

Figure 1b. Equivalent electrical circuit of an oxidized copper electrode at $\mathrm{E}=0.0 \mathrm{~V}$ in a borate buffer solution with $\mathrm{pH} 7.40$.

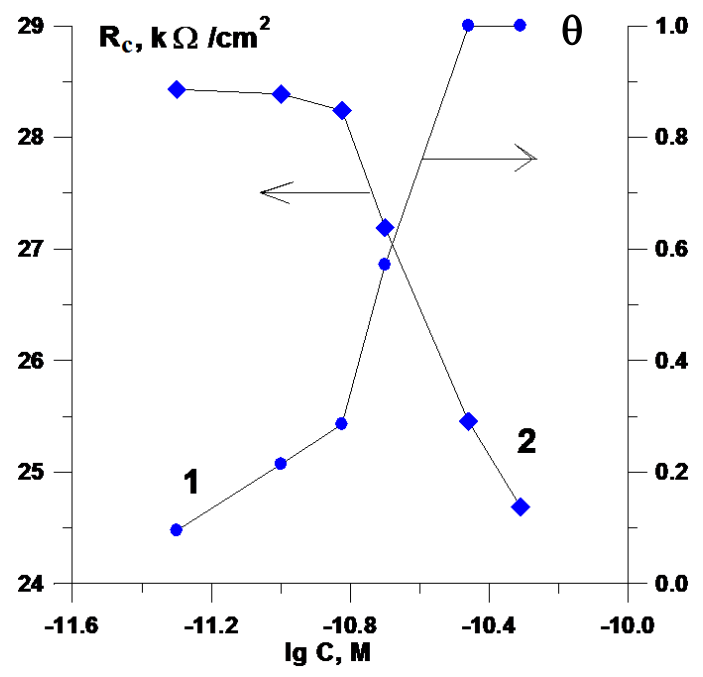

Figure 1c. The dependence of the degree of surface coverage $\theta(1)$ and the resistance of the oxide coating $R_{\mathrm{c}}(2)$ on the logarithm of the concentration of 2-MBT on oxidized copper at $E=0.0 \mathrm{~V}$ in a borate buffer solution, $\mathrm{pH} 7.40$. 
Table 1. Adsorption characteristics of 2-MBT and 3-AT on copper and alloy MNZh 5-1 at different potentials in a borate buffer solution with $\mathrm{pH} 7.40$.

\begin{tabular}{|c|c|c|c|c|c|c|}
\hline \multirow{3}{*}{ Inhibitor } & \multicolumn{3}{|c|}{ Copper } & \multicolumn{3}{|c|}{ MNZh 5-1 alloy } \\
\hline & $\begin{array}{c}\left(-\Delta G_{\mathrm{a}, \text { min }}^{0}\right) \\
\mathbf{k J} / \mathbf{m o l}\end{array}$ & $\begin{array}{c}\left(-\Delta G_{\mathrm{a}, \max }^{0}\right) \\
\mathbf{k J} / \mathbf{m o l}\end{array}$ & $f$ & $\begin{array}{c}\left(-\Delta G_{\mathrm{a}, \min }^{0}\right) \\
\mathbf{k J} / \mathbf{m o l}\end{array}$ & $\begin{array}{c}\left(-\Delta G_{\mathrm{a}, \max }^{0}\right) \\
\mathbf{k J} \mathbf{m o l}\end{array}$ & $f$ \\
\hline & \multicolumn{6}{|c|}{$E=-0.60 \mathrm{~V}$} \\
\hline 2-MBT & 36.8 & 39.2 & 0.81 & 41.4 & 45.6 & 2.56 \\
\hline 3-AT & 27.0 & 28.9 & 0.72 & 32.2 & 34.4 & 0.91 \\
\hline \multirow[t]{2}{*}{ 3-AT (EIS) } & 33.4 & $40.8[28]$ & 2.99 & - & - & - \\
\hline & \multicolumn{6}{|c|}{$E=0.00 \mathrm{~V}$} \\
\hline 2-MBT & 66.7 & $69.0[22]$ & 1.46 & 66.3 & 71.1 & 2.68 \\
\hline 2-MBT (EIS) & 67.2 & 68.4 & 0.96 & & & \\
\hline 3-AT & 56.0 & 57.7 [12] & 1.02 & 61.0 & 68.0 & 2.80 \\
\hline 3- AT (EIS) & 54.9 & $59.3[28]$ & 1.83 & & & \\
\hline
\end{tabular}

The calculation of the EEC elements showed that the resistance $R_{\mathrm{c}}$, which at $E=0.0 \mathrm{~V}$ can be associated with the resistance of $\mathrm{Cu}_{2} \mathrm{O}$, decreases with an increase in $C_{\text {in }}$ (Figure $1 \mathrm{c}$, curve 2). This is most likely due to a decrease in oxide thickness. A similar effect of decreasing the intensity of the Auger spectra of $\mathrm{Cu}_{2} \mathrm{O}$, and hence its thickness, upon addition of 2-MBT was observed in [34]. It was shown [35] that the adsorption of sulfurcontaining compounds on copper can be associated with the interaction of the thiol group with $\mathrm{Cu}_{2} \mathrm{O}$, as a result of which a copper complex is formed on the surface: $\mathrm{Cu}_{2} \mathrm{O}+2 \mathrm{RS}^{-}+$ $\mathrm{H}_{2} \mathrm{O} \rightarrow 2 \mathrm{CuSR}+2 \mathrm{OH}^{-}$.

Thus, it can be considered as proven that at $E=0.0 \mathrm{~V}, 2-\mathrm{MBT}$ is chemisorbed on oxidized copper.

As mentioned above, the adsorption isotherm of 3 -AT on copper at $E=-0.60 \mathrm{~V}$ was obtained by the EIS method [28]. In this case, an EEC consisting of one R-CPE chain was used, from which the $C_{\mathrm{dl}}$ value was determined. The hodograph obtained upon adsorption of 2-MBT is adequately described only if Warburg impedance is added to the circuit. Because of this, it is not possible to unambiguously calculate the true value of $C_{\mathrm{dl}}$, and, therefore, to build the adsorption isotherm.

Corrosion tests in $3.5 \% \mathrm{NaCl}$ (Table 2) were carried out in solutions with different $\mathrm{pH}$, since its value varies greatly depending on the concentration of 2-MBT. The values of $Z$ with respect to different backgrounds are given after a slash. One can see that the difference is high at high corrosion rates and almost negligible at low rates. Addition of 2MBT slow down the corrosion of copper significantly even at $C_{\mathrm{in}}=0.2 \mathrm{mmol} / \mathrm{l}$, and there is practically no corrosion at $0.4 \mathrm{mmol} / \mathrm{l}(Z=98.7 \%)$. 
Table 2. The corrosion rate $K$ and the degree of protection $Z$ for copper samples $\left(S=0.0038 \mathrm{~m}^{2}\right)$ after 7 days of immersion in $3.5 \% \mathrm{NaCl}$ solution.

\begin{tabular}{|c|c|c|c|c|}
\hline Inhibitor & $C_{\mathrm{in}}, \mathrm{mmol} / \mathrm{L}$ & pH solution & $K, \mathrm{~g} / \mathrm{m}^{2}$ days & Degree of protection, $Z, \%$ \\
\hline $\begin{array}{c}\text { Without } \\
\text { inhibitor/without } \\
\text { inhibitor+NaOH }\end{array}$ & 0.00 & $6.4 / 9.2$ & $0.75 / 0.67$ & $-1-$ \\
\hline \multirow{6}{*}{ 3-AT } & 0.10 & 7.25 & 0.23 & $69.3 / 65.7$ \\
\hline & 0.30 & 7.31 & 0.06 & $92.0 / 91.0$ \\
\hline & 0.60 & 7.35 & 0.03 & $96.0 / 95.9$ \\
\hline & 1.00 & 7.38 & 0.006 & $99.5 / 99.1$ \\
\hline & 1.50 & 7.40 & 0.002 & $99.7 / 99.7$ \\
\hline & 2.00 & 7.42 & 0.002 & $99.7 / 99.7$ \\
\hline \multirow{5}{*}{ 2-MBT } & 0.05 & 7.8 & 0.55 & $26.7 / 18.0$ \\
\hline & 0.10 & 8.2 & 0.42 & $44.0 / 37.0$ \\
\hline & 0.20 & 8.7 & 0.04 & $94.7 / 94.0$ \\
\hline & 0.40 & 9.2 & 0.01 & $98.7 / 98.5$ \\
\hline & 0.75 & 9.5 & 0.01 & $98.7 / 98.5$ \\
\hline \multirow{5}{*}{$\mathrm{C}_{11} \mathrm{H}_{23} \mathrm{COONa}$} & 0.05 & 9.3 & 0.20 & $73.3 / 70.1$ \\
\hline & 0.10 & 9.5 & 0.17 & $77.3 / 74.6$ \\
\hline & 0.20 & 9.8 & 0.16 & $78.7 / 76.1$ \\
\hline & 0.40 & 9.9 & 0.13 & $82.7 / 80.6$ \\
\hline & 0.50 & 10.0 & 0.12 & $84.0 / 82.1$ \\
\hline \multirow{6}{*}{$\begin{array}{c}\text { 2-MBT+ } \\
\mathrm{C}_{11} \mathrm{H}_{23} \mathrm{COONa}(1: 1)\end{array}$} & 0.05 & 8.7 & 0.71 & $5.3 /-$ \\
\hline & 0.10 & 9.0 & 0.40 & $46.7 / 40.3$ \\
\hline & 0.15 & 9.1 & 0.24 & $68.0 / 64.2$ \\
\hline & 0.20 & 9.3 & 0.008 & $98.9 / 98.8$ \\
\hline & 0.30 & 9.4 & 0.007 & $99.1 / 99.0$ \\
\hline & 0.40 & 9.6 & 0.007 & $99.1 / 99.0$ \\
\hline
\end{tabular}

It is interesting to compare these results with the protective effect of an organic corrosion inhibitor belonging to another class of compounds, i.e., sodium laurate $\mathrm{C}_{11} \mathrm{H}_{23} \mathrm{COONa}(\mathrm{SL})$. Even at small $C_{\text {in }}=0.05 \mathrm{mmol} / \mathrm{l}$, it reduces the corrosion rate of copper $\sim 4$-fold, but a further increase in $C_{\text {in }}$ almost does not change the corrosion rate. In addition, at $C_{\mathrm{SL}}>0.5 \mathrm{mmol} / 1$ the solubility of the inhibitor decreases due to the "salting-out effect" caused by the high concentration of chlorides. Mixing SL with 2-MBT in an 
equimolar ratio makes it possible to achieve $Z=99 \%$ at $C_{\mathrm{in}}=0.2 \mathrm{mmol} / \mathrm{l}$, i.e. almost complete copper protection. In this case, $C_{2-\mathrm{MBT}}=0.1 \mathrm{mmol} / \mathrm{l}$, i.e. it is 4 times smaller compared with a solution in which 2-MBT itself provides the same protective effect.

Table 3. The corrosion rate $K$ and the degree of protection $Z$ for MNZh 5-1 $\left(S=0.0025 \mathrm{~m}^{2}\right)$ after 7 days of immersion in $3.5 \% \mathrm{NaCl}$ solution.

\begin{tabular}{|c|c|c|c|c|}
\hline Inhibitor corrosion $(\mathbf{C I})$ & $\underset{\mathrm{mmol} / \mathrm{L}}{C_{\mathrm{in}}}$ & pH solution & $\begin{array}{c}\text { Corrosion rate } K, \\
\mathbf{g} / \mathbf{m}^{2} \text { days }\end{array}$ & $\begin{array}{c}\text { Degree of } \\
\text { protection } Z, \%\end{array}$ \\
\hline \multirow{2}{*}{$\begin{array}{c}\text { without } \mathrm{CI} \\
\text { without } \mathrm{CI}+\mathrm{NaOH}\end{array}$} & \multirow{2}{*}{0.0} & 6.4 & 0.88 & - \\
\hline & & 9.2 & 0.62 & 1- \\
\hline \multirow{5}{*}{ 2-MBT } & 0.25 & 8.8 & 0.408 & $54 / 34$ \\
\hline & 0.5 & 9.3 & 0.165 & $81 / 73.3$ \\
\hline & 1.0 & 9.6 & 0.080 & $91 / 87$ \\
\hline & 1.5 & 9.7 & 0.063 & $93 / 90$ \\
\hline & 2.0 & 9.9 & 0.028 & $97 / 95.5$ \\
\hline \multirow{5}{*}{ 3-AT } & 0.5 & 7.34 & 0.21 & $76 / 66$ \\
\hline & 1.0 & 7.38 & 0.17 & $81 / 72.5$ \\
\hline & 1.5 & 7.40 & 0.09 & $90 / 82$ \\
\hline & 2.0 & 7.42 & 0.040 & $95.5 / 93.5$ \\
\hline & 3.0 & 7.43 & 0.016 & $98.2 / 97.4$ \\
\hline \multirow{4}{*}{ 2-MBT+3-AT (1:1) } & 0.25 & 8.62 & 0.20 & 77.2 \\
\hline & 0.50 & 8.70 & 0.06 & 93/90.3 \\
\hline & 1.0 & 8.82 & 0.01 & $98.8 / 98.4$ \\
\hline & 2.0 & 8.98 & 0.0 & $100 / 100$ \\
\hline \multirow{5}{*}{$\begin{array}{c}2-\mathrm{MBT}+\mathrm{C}_{11} \mathrm{H}_{23} \mathrm{COONa} \\
(1: 1)\end{array}$} & 0.05 & 8.7 & 0.69 & 6.8 \\
\hline & 0.10 & 9.0 & 0.39 & 47 \\
\hline & 0.15 & 9.1 & 0.19 & 74 \\
\hline & 0.2 & 9.3 & 0.048 & $93.5 / 92.3$ \\
\hline & 0.25 & 9.4 & 0.005 & $99.3 / 99.2$ \\
\hline \multirow{4}{*}{$\mathrm{C}_{11} \mathrm{H}_{23} \mathrm{COONa}$} & 1.0 & 10.02 & 1.09 & - \\
\hline & 2.0 & 10.17 & 0.96 & - \\
\hline & 5.0 & 10.28 & 0.10 & $88.6 / 84$ \\
\hline & 7.5 & 10.70 & 0.06 & $93.2 / 90$ \\
\hline
\end{tabular}




\section{MNZh 5-1 alloy}

The MNZh 5-1 alloy has a higher resistance to the corrosive action of chlorides than copper [22, 30-32]. For example, addition of $20 \mathrm{mmol} / \mathrm{l} 3$-AT is required to suppress the anodic dissolution of copper in a borate buffer containing $10 \mathrm{mmol} / \mathrm{l} \mathrm{NaCl}$, which is 2 times higher than the concentration of $\mathrm{NaCl}$. For a similar effect on the alloy, $7 \mathrm{mmol} / \mathrm{l} 3$ AT is sufficient, which is almost 3 times lower than for copper (Figure 2a). Smaller 3-AT concentrations $\left(C_{\text {in }} \geq 0.12 \mathrm{mmol} / \mathrm{l}\right)$ suppress the first anodic current peak on the polarization curve of the alloy and increase the $E_{\mathrm{ld}}$ by at least $0.18 \mathrm{~V}$. Addition of 3.0 and $5.0 \mathrm{mmol} / \mathrm{l} 3$ AT also practically suppresses the second anodic peak and $E_{\mathrm{ld}}$ increases by 0.26 and $0.35 \mathrm{~V}$, respectively.

2-MBT begins to exhibit protective properties to copper in a similar solution at $C_{\text {in }}=1.1 \mathrm{mmol} / 1$ [22]. On the MNZh 5-1 alloy, $0.10 \mathrm{mmol} / \mathrm{l}$ is sufficient to suppress the first anodic peak, and a further increase in $C_{\text {in }}$ shifts $E_{\mathrm{ld}}$ in the positive direction and reduces the current densities of both peaks until they disappear at $C_{\text {in }}=0.15 \mathrm{mmol} / \mathrm{l}$ (Figure 2b). At $0.25 \mathrm{mmol} / \mathrm{l}, 2-\mathrm{MBT}$ forms such a stable passive film that it prevents not only local depassivation but also anodic oxygen evolution.

The use of equimolar formulations of 2-MBT with sodium laurate (Figure 2c) and 3AT (Figure 2d) leads to the protection of the MNZh 5-1 alloy from local depassivation in chloride buffer solution at lower concentrations than 3-AT and sodium laurate individually.

The ability of the studied compounds to passivate the alloy at such low $C_{\text {in }}$ is undoubtedly associated with their strong adsorption on the surface to be protected and the formation of hardly soluble complex compounds with the metals that constitute the alloy, primarily with $\mathrm{Cu}(\mathrm{I})$. It is possible to estimate the free adsorption energy during the formation of the first monolayer on the alloy surface using the in situ ellipsometric method. At the same time, it is possible to compare their adsorption at different electrode potentials, which allows us to evaluate the effect of the state of the alloy surface on adsorption: at $E=-0.60 \mathrm{~V}$, when it is free of oxides, and at $E=0.0 \mathrm{~V}$ on a pre-oxidized alloy surface.

On the oxide-free copper surface, the adsorption of both compounds under study begins at $C_{\mathrm{in}}: 0.08 \mathrm{mmol} / 1$ for $3-\mathrm{AT}$ and $0.004 \mathrm{mmol} / \mathrm{l}$ for 2-MBT (Figures 3 and 4). The adsorption of these compounds on the alloy begins at lower $C_{\text {in }}$ : this is $C_{\text {in }}=0.056 \mathrm{mmol} / \mathrm{l}$ for 3-AT and $C_{\text {in }}=0.4 \mathrm{mmol} / 1$ for $2-\mathrm{MBT}$.

This was to be expected from a comparison of the anodic polarization curves of the alloy and copper [22]. For 3-AT adsorption on the alloy at $E=-0.60 \mathrm{~V}$, the first small plateau of $(-\delta \Delta)$ at $0.17-0.18^{\circ}$ can be distinguished, which is shown in Figure 3a with a dashed line. It may correspond to a monolayer surface coverage. The values of $\left(-\Delta G_{\mathrm{a}, \max }^{0}\right)$ calculated by Equation 2 for 2-MBT and 3-AT are given in Table 1. The free adsorption energy of 2-MBT is $39.2 \mathrm{~kJ} / \mathrm{mol}$, which is by $10 \mathrm{~kJ} / \mathrm{mol}$ higher than that of $3-\mathrm{AT}$. 


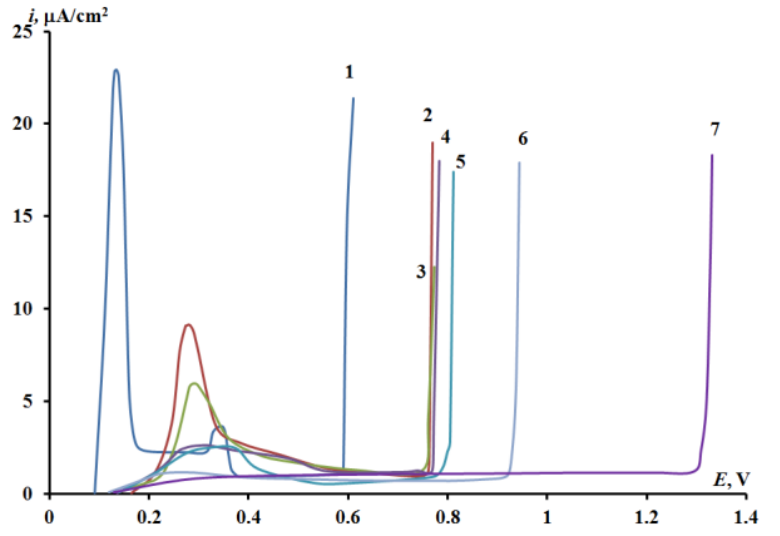

a)

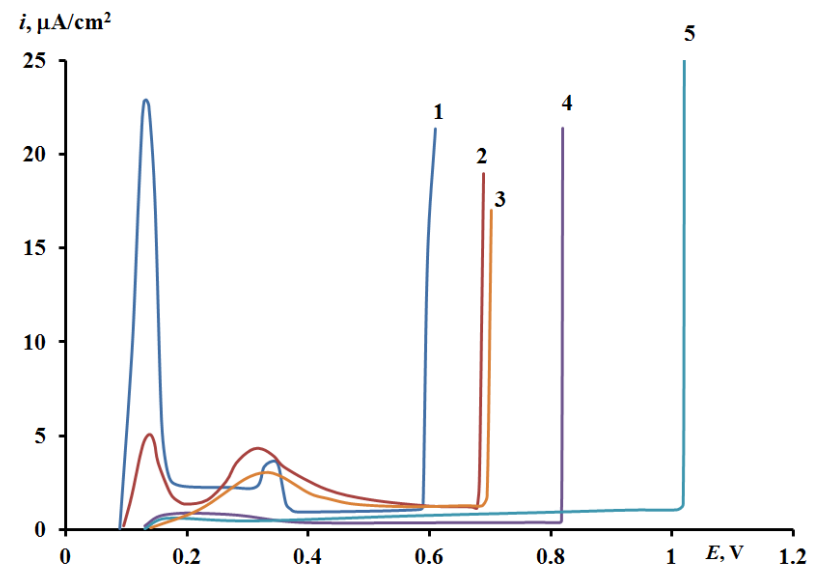

c)

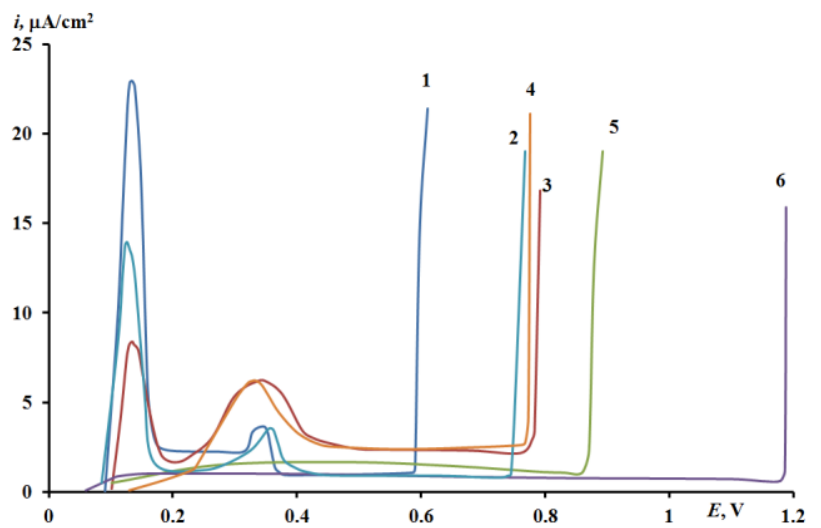

b)

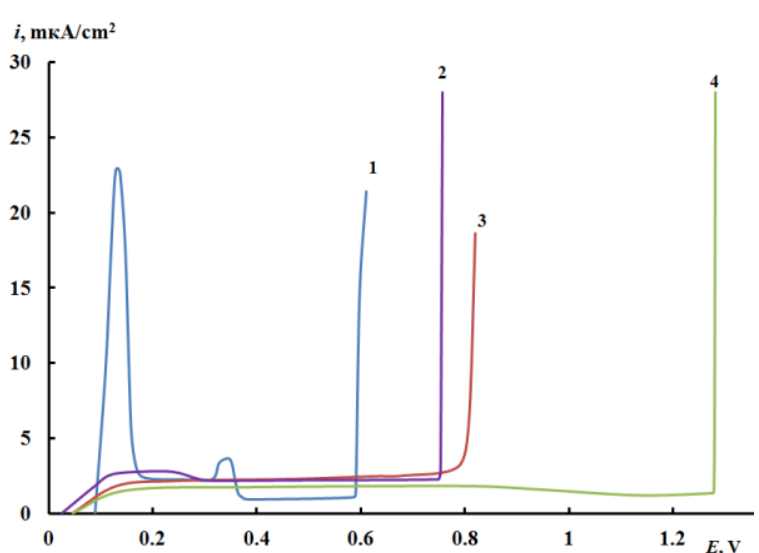

d)

Figure 2. Polarization curves of MNZH 5-1 in a borate buffer with $\mathrm{pH} 7.40$, containing:

(1) $10 \mathrm{mmol} / \mathrm{l}$ of $\mathrm{NaCl}$ with and without added inhibitor, $C_{\text {in }}$ (in $\mathrm{mmol} / \mathrm{l}$ ): 3 -AT: $2-0.12 ; 3-$ $0.25 ; 4-0.50 ; 5-1.5 ; 6-3.0 ; 7-5.0 ; 8-7.0 ; 2$-MBT: $2-0.03 ; 3-0.06 ; 4-0.10 ; 5-0.15$; $6-0.25 ; 2-\mathrm{MBT}+\mathrm{C}_{11} \mathrm{H}_{23} \mathrm{COONa}(1: 1): 2-0.06 ; 3-0.08 ; 4-0.20 ; 5-0.25 ; 2-\mathrm{MBT}+3-\mathrm{AT}$ $(1: 1): 2-0.13 ; 3-0.25 ; 4-0.50$.

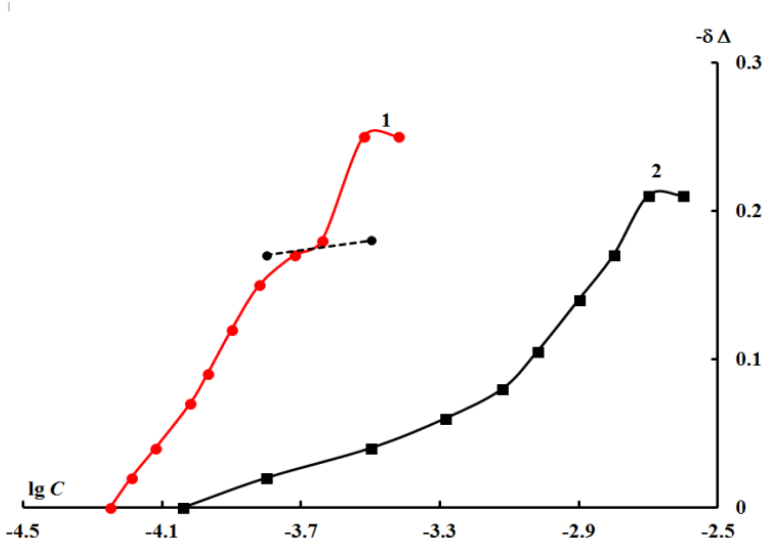

a)

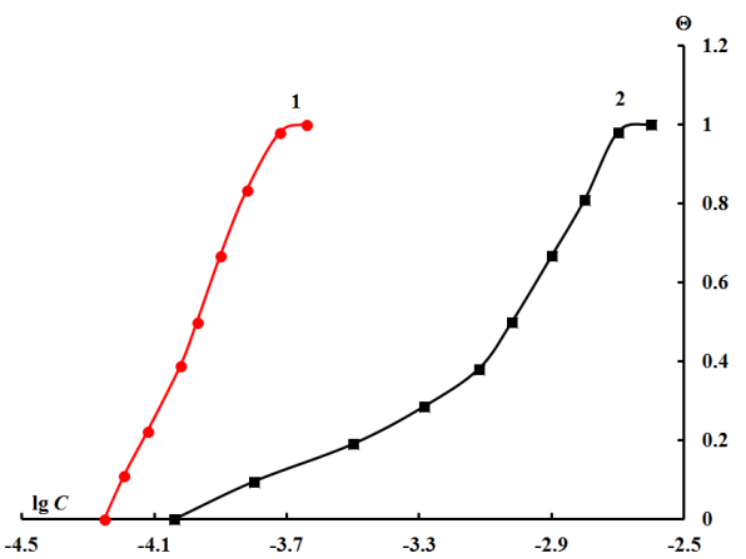

b)

Figure 3. Dependence of the change in the ellipsometric angle $(\Delta)$ (a) and the degree of surface coverage $\theta$ (b) on the logarithm of 3-AT concentration on reduced surface of MNZh 51 alloy (1) and copper (2) [12] at $E=-0.60 \mathrm{~V}$ in borate buffer solution with $\mathrm{pH} 7.40$. 


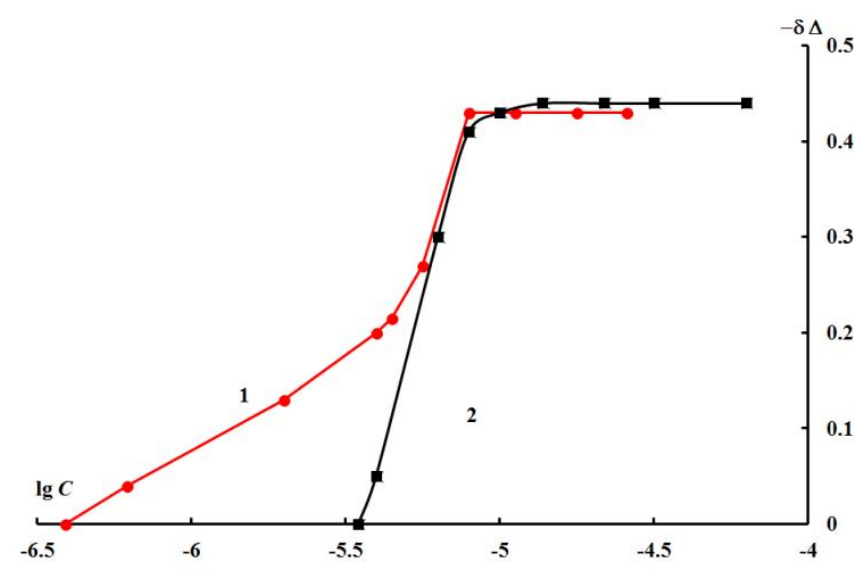

a)

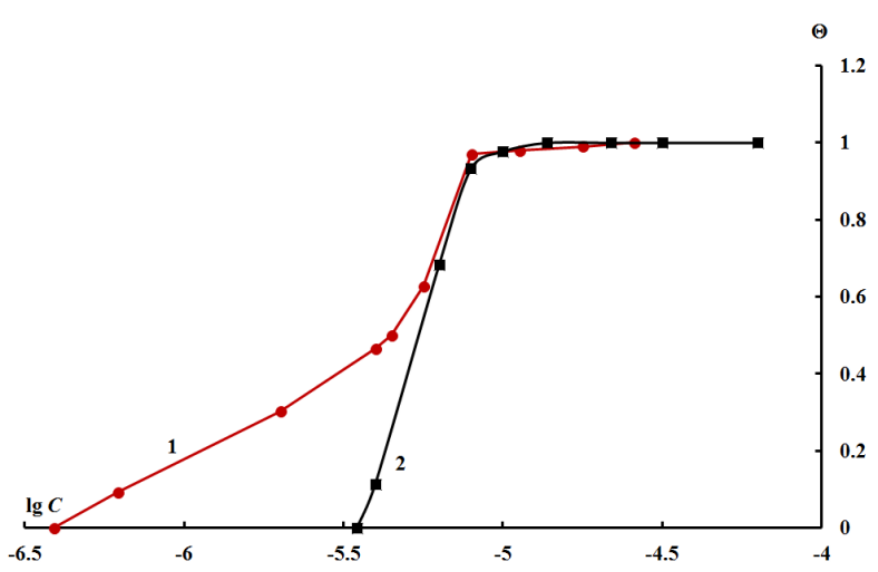

b)

Figure 4. Dependence of the change in the ellipsometric angle $(\Delta)$ (a) and the degree of surface coverage $\theta$ (b) on the logarithm of 2-MBT concentration on reduced surfaces of the MNZh 5-1 alloy (1) and copper (2) at $E=-0.60 \mathrm{~V}$ in borate buffer with $\mathrm{pH} 7.40$.

It is interesting that the factor of surface heterogeneity $f$ sharply increases in the case of adsorption of 2-MBT on the alloy compared with adsorption on copper. The adsorption of 3-AT is less sensitive to changes on the reduced electrode surface on passage from copper to the alloy.

If cuprite $\mathrm{Cu}_{2} \mathrm{O}$ is already present on the surface of copper and alloy at $E=0.0 \mathrm{~V}$, then this can improve the adsorption of 3-AT and 2-MBT (Figure 5). The isotherms of these compounds originate in the region of lower $C_{\text {in }}$ than for the oxide-free surface. For 3-AT on the surface of MNZh 5-1 and copper at $E=0.0 \mathrm{~V}$, adsorption begins at $C_{\text {in }}$ values that are by several orders of magnitude smaller and is characterized by $\left(-\Delta G_{\mathrm{a}, \max }^{0}\right)=68$ and $59 \mathrm{~kJ} / \mathrm{mol}$, respectively (Table 1). This is 2 times higher for both metals than for 3-AT adsorption on the reduced surface.

Adsorption on oxidized copper is also characterized by a larger $\left(-\Delta G_{\mathrm{a}, \max }^{0}\right)$ value than on reduced surface, also 2.2 times for 3-AT and 1.95 times for 2-MBT. The $f$ coefficient in these cases also becomes higher, which is especially pronounced in the case of 3-AT, which, apparently, acquires the ability to be strongly chemisorbed on oxidized surfaces.

The thicknesses of 3-AT and 2-MBT monolayers on the surface of copper and MNZh 5-1 alloy were determined from the results of ellipsometric measurements according to the technique described previously [11]. The proportionality coefficient in Equation (1) is $\alpha=0.89 \mathrm{~nm} / \mathrm{deg}$ for copper and $\alpha=0.77 \mathrm{~nm} / \mathrm{deg}$ for the alloy. The thicknesses obtained on the oxidized surface of the MNZh 5-1 alloy were as follows: $\left(-\delta \Delta=0.44^{\circ}\right), d=$ $0.34 \pm 0.1 \mathrm{~nm}$ for 3 -AT and $\left(-\delta \Delta=0.49^{\circ}\right), d=0.37 \pm 0.1 \mathrm{~nm}$ for 2-MBT. The sizes of the molecules of these inhibitors calculated from the bond lengths of their constituents are $0.50-0.60 \mathrm{~nm}$ for 3-AT and $0.82 \mathrm{~nm}$ for 2-MBT [22]. It can be assumed that the 3-AT molecule is in an upright position in the monolayer, and 2-MBT is adsorbed in a more planar manner by forming bonds with the copper surface through a nitrogen atom and an 
exo-sulfur atom. This regularity also repeats on the oxidized surface of copper: 3-AT is vertically located in a monolayer [12] whereas 2-MBT is in a more slanted position [22].

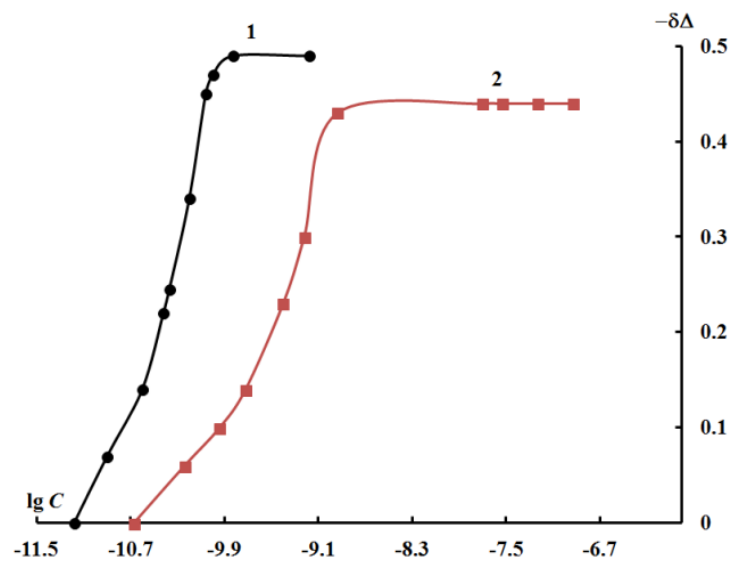

a)

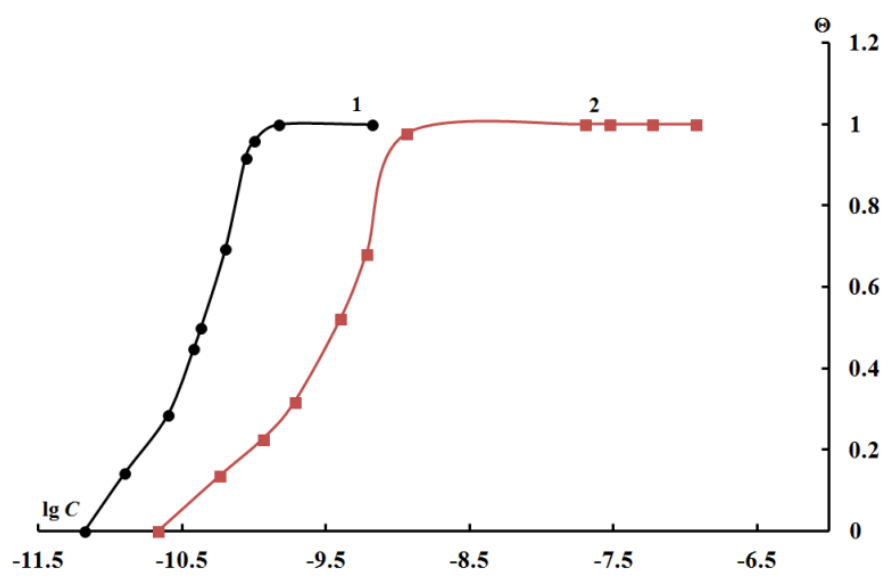

b)

Figure 5. Dependence of the change in the ellipsometric angle $(\Delta)$ (a) and the degree of surface coverage $\theta$ (b) on the logarithm of 2-MBT (1) and 3-AT concentrations (2) on the oxidized surface of the MNZh 5-1 alloy at $E=0.0 \mathrm{~V}$ in borate buffer, $\mathrm{pH}$ 7.40.

On oxide-free surfaces of copper and alloy, the thickness of the monolayers is smaller. The thickness of the conditional 3-AT monolayer is $\left(-\delta \Delta=0.18^{\circ}\right), d=$ $0.14 \pm 0.1 \mathrm{~nm}$ on MNZh $5-1$ and $\left(-\delta \Delta=0.20^{\circ}\right), d=0.20 \pm 0.1 \mathrm{~nm}$ on copper. These values indicate an almost planar arrangement of 3-AT on a "clean" surface. For 2-MBT, the thickness of the conditional monolayer little differs on the alloy and copper $\left(-\delta \Delta=0.44^{\circ}\right)$, $d=0.34-0.4 \pm 0.1 \mathrm{~nm}$ and corresponds to a more horizontal arrangement of molecules in the monolayer.

Gravimetric corrosion tests on MNZh 5-1 plates showed that at $C_{\text {in }}=0.50 \mathrm{mmol} / \mathrm{l}$, the corrosion rate is reduced 5-fold by 2-MBT and 4-fold by 3 -AT. At almost all of the $C_{\text {in }}$ values studied, 2-MBT shows the best protection, while the corrosion rate $K$ and degree of protection $Z$ have a more significant tendency to decrease than at similar 3-AT concentrations. At $C_{\mathrm{in}}=2 \mathrm{mmol} / \mathrm{l}$, the degree of protection reaches $97 \%$ and $95.5 \%$ for 2 MBT and 3-AT, respectively.

An equimolar mixture of 2-MBT $+3-\mathrm{AT}$ reduces the corrosion rate 4-fold at $C_{\mathrm{in}}=0.25 \mathrm{mmol} / \mathrm{l}$ and 16 -fold at $0.50 \mathrm{mmol} / \mathrm{lcompared}$ with the uninhibited solution. It should be noted that the mixture is more efficient than each of the components alone. For example, at $C_{\mathrm{in}}=1.0 \mathrm{mmol} / \mathrm{l}$, the degree of protection provided by $2-\mathrm{MBT}$ is $Z=91 \%$, that of 3-AT is $Z=81 \%$, while their formulation provides $98.8 \%$.

Another equimolar formulation of 2-MBT with sodium laurate also shows a high degree of corrosion protection in $3.5 \%$ sodium chloride solution. $0.25 \mathrm{mmol} / \mathrm{l}$ of this

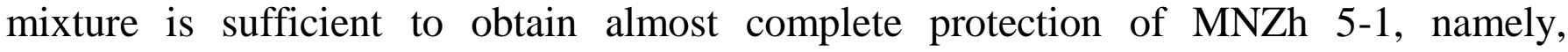
$Z=99.3 \%$. The 2-MBT $+\mathrm{C}_{11} \mathrm{H}_{23} \mathrm{COONa}$ mixture (1:1) significantly exceeds its components. 
Both developed formulations efficiently protect the alloy from corrosion damage in corrosive sodium chloride solution. The formulation of 2-MBT with sodium laurate is more efficient than 2-MBT +3-AT.

\section{Conclusions}

1. A combination of electrochemical, ellipsometric and gravimetric studies showed that 2MBT is a more efficient corrosion inhibitor of copper and MNZh 5-1 alloy than 3-AT in a neutral chloride solution.

2. 2-MBT is adsorbed on oxidized copper better than 3-AT, apparently due to interaction with its oxide, which allows it to form the protective coating on the surface that protects the metal well even at high chloride concentrations.

3. The studied inhibitors form a monolayer on reduced copper surface, while on the alloy, complex compounds continue to grow after the formation of a conditional monolayer. The 2-MBT molecule is adsorbed in planar orientation on reduced and oxidized surfaces of copper and MNZh 5-1, forming bonds with the surface through sulfur and nitrogen atoms. The 3-AT molecule on the oxide-free surfaces of the alloy and copper is in a planar orientation, but at the anodic potential it is in a nearly vertical position.

4. An equimolar formulation of 2-MBT+sodium laurate was developed, which showed high efficiency for copper and its alloy in $3.5 \%$ sodium chloride solution.

\section{References}

1. I.T. Vargas, D.A. Fisher, M.A. Alsina, J.P. Pavissich, P.A. Pasten and G.E. Pizzaro, Copper corrosion and biocorrosion events in premise plumbing, Mater., 2017, 10, no. 9, 1036. doi: $10.3390 / \mathrm{ma10091036}$

2. A.A. Mikhailov, Yu.M. Panchenko and Yu.I. Kuznetsov, Atmospheric corrosion and protection of metals, 2016, Tambov, Pershin Publishing House, 555 (in Russian).

3. Compositions for inhibiting metal tarnish, British Patent 625 339, Procter and Gamble Ltd., 09.12.1947.

4. I. Dugdale and J.B. Cotton, An electrochemical investigation on the prevention of staining of copper by benzotriazole, Corros. Sci., 1963, 3, no. 2, 69-74. doi: 10.1016/S0010-938X(63)80001-3

5. Yu.I. Kuznetsov and L.P. Podgornova, Ingibirovanie korrozii metallov heterotsiklicheskimi khelatoreagentami (Inhibition of metals corrosion by heterocyclic helatoreagents). In the book: Korroziya I Zaschita ot korrozii (Itogi Nauki i Techniki) [Corrosion and Corrosion Prevention (Advances in Science and Engineering Series)], Moscow, VINITI, 1989, no. 15, 132-184 (in Russian).

6. Yu.I. Kuznetsov and L.P. Kazansky, Physicochemical aspects of metal protection by azoles, Russ. Chem. Rev., 2008, 77, no. 3, 219-232 (in Russian). doi: 10.1070/RC2008v077n03ABEH003753 
7. N.K. Allam, A.A. Nazeer and E.A. Ashour, A review of the effects of benzotriazole on the corrosion of copper and copper alloys in clean and polluted environments, J. Appl. Electrochem., 2009, 39, 961-969. doi: 10.1007/s10800-009-9779-4

8. Matjaž Finšgar and Ingrid Milošev, Inhibition of copper corrosion by 1,2,3benzotriazole: A review, Corros. Sci., 2010, 52, no. 9, 2737-2749. doi: 10.1016/j.corsci.2010.05.002

9. M.B. Petrović Mihajlović and M.M. Antonijević, Copper corrosion inhibitors, Period 2008-2014. A review, Int. J. Electrochem. Sci., 2015, no. 10, 1027-1053.

10. A. Kokalj, Ab initio modeling of the bonding of benzotriazole corrosion inhibitor to reduced and oxidized copper surfaces, Faraday Discuss., 2015, no. 180, 415-438. doi: 10.1039/C4FD00257A

11. M.O. Agafonkina, N.P. Andreeva, Yu.I. Kuznetsov and S.F. Timashev, Substituted benzotriazoles as inhibitors of copper corrosion in borate buffer solutions, Russ. J. Phys. Chem., 2017, 91, no. 8, 1414-1421. doi: 10.1134/S0036024417080027

12. A.A. Chirkunov, Yu.I. Kuznetsov, Kh.S. Shikhaliev, M.O. Agafonkina, N.P. Andreeva, L.P. Kazansky and A.Yu. Potapov, Adsorption of 5-alkyl-3-amino-1,2,4-triazoles from aqueous solutions and protection of copper from atmospheric corrosion, Corros. Sci., 2018, 144, 230-236. doi: 10.1016/j.corsci.2018.08.056

13. Yu.I. Kuznetsov, Triazoles as a class of multifunctional corrosion inhibitors. A review, Part I. 1,2,3-Benzotriazole and its derivatives, Copper, zinc and their alloys, Int. J. Corros. Scale Inhib., 2018, 7, no. 3, 271-307. doi: 10.17675/2305-6894-2018-7-3-1

14. Ž.Z. Tasić, M.B. Petrović Mihajlović, M.B. Radovanović and M.M. Antonijević, New trends in corrosion protection of copper, Chem. Pap., 2019, no. 73, 2103-2132. doi: 10.1007/s11696-019-00774-1

15. Abdul Shaban, Gyöngyi Vastag and Ilona Felhősi, Micro- and nano-electrochemical investigations of copper corrosion and its inhibition with selected organic molecules, Int. J. Nano Corr. Sci. and Engg., 2017, 4, no. 1, 11-30.

16. J. Bregman, Corrosion Inhibitor, 1963, New York, The MacMillan Company, p. 310.

17. Yu.I. Kuznetsov and L.P. Podgornova, Inhibition of copper and zinc dissolution in phosphate solutions by benzothiazoles, Prot. Met., 1993, 29, no. 3, 471-478 (in Russian).

18. Yu.I. Kuznetsov, New possibilities of metal corrosion inhibition by organic heterocyclic compounds, Int. J. Corros. Scale Inhib., 2012, 1, no. 1, 3-15. doi: 10.17675/2305-6894-2012-1-1-003-015

19. M.M. Musiani, G. Mengoli, M. Fleishmann and R.B. Lowry, Electrochemical and SERS investigation of the influence of $\mathrm{pH}$ on the effectiveness of some corrosion inhibitors of copper, J. Electroanal. Chem., 1987, 217, 187-202. doi: 10.1016/0022$\underline{0728(87) 85073-8}$

20. H. Nishizawa, O. Sugiura, Y. Matsumura and M. Kinoshita, Evaluation of mercaptobenzothiazole anticorrosive layer on $\mathrm{Cu}$ surface by spectroscopic ellipsometry, Jpn. J. Appl. Phys., 2007, 46, 2892-2894. doi: 10.1143/JJAP.46.2892 
21. L.P. Kazansky, I.A. Selyaninov and Yu.I. Kuznetsov, Adsorption of 2mercaptobenzothiazole on copper surface from phosphate solutions, Appl. Surf. Sci., 2012, 258, 6807-6813. doi: 10.1016/j.apsusc.2012.03.097

22. M.O. Agafonkina, Yu.I. Kuznetsov, N.P. Andreeva, Kh.S. Shikhaliev and A.Yu. Potapov, Adsorbtsiya i passivatsiya medi S-soderzhashchimi geterotsiklicheskimi soedineniyami v neitral'nykh vodnykh rastvorakh (Adsorption and passivation of copper by S-containing heterocyclic compounds in neutral aqueous solutions), Korroz.: mater., zashch. (Corrosion: materials, protection), 2017, no. 11, 25-31 (in Russian).

23. M. Finšgar and D. Kek Merl, An electrochemical, long-term immersion and XPS study of 2-mercaptobenzothiazole as a copper corrosion inhibitor in chloride solution, Corros. Sci., 2014, 83, 164-175. doi: 10.1016/j.corsci.2014.02.016

24. L.P. Kazansky, Yu.E. Pronin and I.A. Arkhipushkin, XPS study of adsorption of 2mercaptobenzothiazole on a brass surface, Corros. Sci., 2014, 89, 21-29. doi: 10.1016/j.corsci.2014.07.055

25. Yu.I. Kuznetsov, Organic corrosion inhibitors: Where are we now? Part I. Adsorption, Int. J. Corros. Scale Inhib., 2015, 4, no. 4, 284-310. doi: 10.17675/2305-6894-2015-4$\underline{4-1}$

26. Yu.I. Kuznetsov, M.O. Agafonkina, N.P. Andreeva and L.P. Kazansky, Adsorption of dimegin and inhibition of copper dissolution in aqueous solutions, Corros. Sci., 2015, 100, 535-543. doi: 10.1016/j.corsci.2015.08.028

27. Yu.I. Kuznetsov, Kh.S. Shikhaliev, M.O. Agafonkina, N.P. Andreeva, A.M. Semiletov, A.A. Chirkunov, A.Yu. Potapov and V.E. Solov'ev, Formation of passivating layers by 1,2,4-triazole derivatives on copper in aqueous solutions, Russ. J. Phys. Chem., 2017, 91, no. 12, 2455-2462. doi: 10.1134/S0036024417120147

28. Yu.I. Kuznetsov, D.B. Vershok and N.P. Andreeva, Vliyaniye potentsiala elektrodov na adsorbtsiyu nekotorykh triazolov v boratnom bufere (Effect of elecyrode potential on the adsorption of some triazoles), Korroz.: mater., zashch. (Corrosion: materials, protection), 2018, no. 12, 20-25 (in Russian).

29. I.A. Arkhipushkin, M.O. Agafonkina, L.P. Kazansky, Yu.I. Kuznetsov and Kh.S. Shikhaliev, Characterization of adsorption of 5-carboxy-3-amino-1,2,4-triazole towards copper corrosion prevention in neutral media, Electrochim. Acta, 2019, 308, 392-399. doi: 10.1016/j.electacta.2019.04.014

30. M.O. Agafonkina, Yu.I. Kuznetsov and N.P. Andreeva, Adsorbtsiya anionov karbonovykh kislot na splave MNZH 5-1 iz neytral'nykh vodnykh rastvorov (Adsorption of carboxylate anions on MNZh 5-1 alloy from neutral aqueous solutions), Korroz.: mater., zashch. (Corrosion: materials, protection), 2019, no. 8, 29-35 (in Russian).

31. Yu.I. Kuznetsov, N.P. Andreeva and M.O. Agafonkina, Adsorption and protecting properties of 1,2,3-benzotriazole on MNZh 5-1 alloy in neutral solutions, Russ. J. Electrochem., 2014, 50, no. 10, 989-993. doi: 10.1134/S1023193514100048 
32. Yu.I. Kuznetzov, M.O. Agafonkina, N.P. Andreeva, I.A. Arkhipushkin and L.P. Kazansky, Inhibiting the corrosion of MNZh 5-1 alloy in neutral solutions of 5chloro-1,2,3-benzotrialzol, Russ. J. Phys. Chem. A, 2017, 91, no. 11, 2226-2233. doi: $10.1134 / \mathrm{S} 0036024417110127$

33. U. Rammelt and G. Reinhard, On the applicability of a constant phase element (CPE) to the estimation of roughness of solid metal electrodes, Electrochim. Acta, 1990, 35, no. 6, 1045-1049.

34. I.A. Arkhipushkin, Yu.E. Pronin, S.S. Vesely and L.P. Kazansky, Electrochemical and XPS study of 2-mercaptobenzothiazole nanolayers on zinc and copper surface, Int. J. Corros. Scale Inhib., 2014, 3, no. 2, 78-88. doi: 10.17675/2305-6894-2014-3-2-078$\underline{088}$

35. C.A. Calderón, C. Ojeda, V.A. Macagno, P. Paredes-Olivera and E.M. Patrito, Interaction of oxidized copper surfaces with alkanethiols in organic and aqueous solvents. The mechanism of $\mathrm{Cu}_{2} \mathrm{O}$ reduction, J. Phys. Chem. C, 2010, 114, 3945-3957. doi: $\underline{10.1021 / j p 9045148}$ 